Marquette University

e-Publications@Marquette

$11-1-2012$

\title{
Investors Do Respond to Poor Mutual Fund Performance: Evidence from Inflows and Outflows
}

George D. Cashman

Marquette University, george.cashman@marquette.edu

Daniel N. Deli

DePaul University

Federico Nardari

University of Houston

Sriram V. Villupuram

Colorado State University - Fort Collins

Accepted version. The Financial Review, Vol 47, No. 4 (November 2012): 719-739. DOI. (C) 2012 John Wiley \& Sons, Inc. Used with permission.

George D. Cashman was affiliated with Texas Tech University at the time of publication. 
Marquette University

\title{
e-Publications@Marquette
}

\section{Finance Faculty Research and Publications/College of Business Administration}

This paper is NOT THE PUBLISHED VERSION; but the author's final, peer-reviewed manuscript. The published version may be accessed by following the link in the citation below.

The Financial Review, Vol. 47, No. 4 (2012): 719-739. DOI. This article is (C) Eastern Finance Association and permission has been granted for this version to appear in e-Publications@Marquette. Eastern Finance Association does not grant permission for this article to be further copied/distributed or hosted elsewhere without the express permission from Eastern Finance Association.

\section{Investors Do Respond to Poor Mutual Fund Performance: Evidence from Inflows and Outflows}

George D. Cashman

Texas Tech University

Daniel N. Deli

DePaul University

Federico Nardari

University of Houston

Sriram Villupuram

Colorado State University

\begin{abstract}
We examine the relation between mutual fund performance and gross flows for a large sample of actively managed U.S. mutual funds. Unlike previous studies that have only examined periods of generally increasing net flows, our sample includes periods of both increasing and decreasing net flows. We find that outflows are related to performance, with investors withdrawing money from poor performers. We also find that outflows and inflows respond asymmetrically to performance, outflows
\end{abstract}


increase more aggressively following poor performance, and inflows increase more aggressively following good performance. Additionally, we find a symmetric performance net flow relation.

\section{Introduction}

The nonlinear relation between annual mutual fund performance and subsequent annual net flows is one of the best documented empirical regularities in mutual fund research. There are two explanations for the observed nonlinear relation between performance and net flows. The first argues that the nonlinearity results from a lack of a response to poor performance (e.g., Gruber, 1996; Lynch and Musto, 2003; Ivkovic and Weisbenner, 2009). These papers argue that investors fail to withdraw money from poorly performing funds for various rational and irrational reasons. The alternative explanation proposed by Huang, Wei and Yan (2007) switches the focus from a lack of a response to poor performance to a disproportionate response to good performance. Huang, Wei and Yan (2007) argue that participation costs make responding to lesser performance too costly.

However, both of these explanations are based on examinations of net flows. We examine the performance gross flow relation to provide a more detailed picture of how investors respond to fund performance. Unlike earlier studies of gross flows that used limited nonrandom samples, we examine the gross flows of more than 3,200 actively managed domestic equity funds for the period 1997-2007. In addition to its sheer size, our sample offers the advantage of containing periods of both generally increasing and decreasing net flows. We find the following. First, existing investors punish poor performance by increasing outflows. Second, both outflows and inflows respond asymmetrically to performance-poor performance results in large outflows just as good performance results in large inflows. Third, net flows respond to both good and bad performance symmetrically; this result runs in stark contrast to the asymmetric relation between performance and net flows documented in prior studies. Finally, we find no evidence that participation costs influence the relation between performance and flows.

Our results are of interest to academics and practitioners for several reasons. From an academic perspective, our findings offer a broader insight into the trading decisions of mutual fund investors. They suggest that the previously observed nonlinear relation between performance and net flows was not, in fact, driven by a lack of response of existing investors to bad performance, but more likely was driven by sample period and/or sample construction. As in unreported tests, limiting the sample to pre-2003, we find a nonlinear performance flow relation consistent with prior research. Also, our results suggest that investors believe that fund performance signals managerial skill. That result confirms a basic assumption in models such as Berk and Green (2004). Finally, our results suggest that current investors continue to monitor mutual fund managers, withdrawing their money in response to poor performance, which is contrary to Johnson (2007).

From a practitioner's perspective, understanding the relation between performance and flows is vital for business planning. Over the 12-year period from 1989 to 2000, net flows to equity mutual funds increased from $\$ 6.8$ billion to more than $\$ 309$ billion (a 45 -fold increase, according to the Investment Company Institute's Fact Book, 2010). Since the peak in 2000, however, net flows have been declining. Results from previous studies potentially misrepresent the relation between performance and flows because of their sample periods. For example, two well-known studies on the performance flow relation (Chevalier and Ellison, 1997; Sirri and Tufano, 1998) use samples from 1983 to 1993 and from 
1970 to 1990, respectively. Both studies only include periods of generally increasing net flows. More recent studies (e.g., Bergstresser and Poterba, 2002; Johnson, 2007; Ivkovic and Weisbenner, 2009) also examine periods of generally increasing net flows. Our results, based on a sample including both periods of increasing and decreasing net flows, suggest a different relation between performance and net flows. Specifically, that net flows respond symmetrically to performance. This result is important because the large demographic group of Baby Boomers is starting to transition from saving for retirement to spending (dis-saving) in retirement, implying a general decline in net flows for the near term. That, in turn, suggests that the largely symmetric relation we observe between performance and net flows is likely to continue, at least through the end of the demographic cycle.

\section{Research background}

\subsection{Lack of an outflow response to poor performance}

As noted earlier, there are two primary explanations for the nonlinear relation between performance and net flows. The first focuses on the nonresponsiveness of net flows to poor performance, arguing that existing investors fail to withdraw funds following poor performance. For example, Gruber (1996) suggests that there are two clienteles of mutual fund investors-sophisticated investors and disadvantaged investors. Disadvantaged investors fail to respond to poor performance because either they are influenced by factors other than return (such as advertising or advice from brokers) or they face some sort of friction that makes withdrawals costly. Investor heterogeneity produces the asymmetric performance net flow relation. 1

Rather than relying on investor heterogeneity, Lynch and Musto (2003) suggest that investors in poorly performing funds rationally choose not to withdraw their investment. They argue that following poor performance, fund sponsors will change the portfolio management strategy and/or the management team. Therefore, investors have no reason to believe that the poor performance will persist. Thus, current investors rationally choose not to withdraw their investment in poorly performing funds.

Ivkovic and Weisbenner (2009) introduce the possibility that inactivity by existing investors in the face of poor performance is a manifestation of the disposition effect (e.g., Kahneman and Tversky, 1979; Shefrin and Statman, 1985). Specifically, investors may have an aversion to realizing losses, which leads them to leave their money in poorly performing funds.

Results from previous empirical studies of gross flows generally are consistent with the notion that current investors in a fund fail to respond to poor performance. Bergstresser and Poterba (2002), Johnson (2007), and Ivkovic and Weisbenner (2009) all fail to find a relation between poor (relative) performance and outflows. 2 However, it must be noted, that these studies examine limited nonrandom samples. For example, Bergstresser and Poterba (2002) only examine the 200 largest mutual funds. O'Neal (2004) contends that the relations observed in this sample may not be representative of the mutual fund universe, as a whole. Johnson (2007) studies less than ten funds, all from a single no-load fund family. Ivkovic and Weisbenner (2009) examine only the trading behavior of retail investors within a single discount brokerage. Johnson (2007) presents evidence that mutual fund investors who use a discount brokerage house are not representative of the wider mutual fund investor universe, questioning the generalizability of Ivkovic and Weisbenner's (2009) findings. Additionally, Christoffersen, Evans and Musto (2007) argue that relying on account level data, like those used by Johnson (2007) and Ivkovic and Weisbenner (2009), is potentially problematic, as the samples are compiled using limited nonrandom samples of investors and funds. 


\subsection{Inflow response to superior performance}

An alternative explanation for the nonlinear performance net flow relation focuses on new investors entering the fund in response to superior performance. Huang, Wei and Yan (2007) argue that investors use performance as a signal of managerial ability. Participation costs, however, make it rational to respond to only the best performance. The result is that investors are insensitive to poor and moderate performance and respond to only the best performance.

\subsection{An additional empirical study}

O'Neal (2004) examines the relation between performance and annual gross flows for the 200 largest mutual funds. He claims to "document that investors punish poor performance with increased redemptions." Oddly, though, if punishing poor performance is defined as increasing outflows in response to poor performance, O' Neal (2004) finds no evidence that investors actually punish poor performance. What O'Neal (2004) does find is that outflows for funds with average and above-average performance tend to decrease as performance increases (for certain measures of performance), with the negative relation being most pronounced for the best performing funds (see his table III). He finds no relation between performance and outflows among those funds with the worst performance. Thus, O'Neal's results are more appropriately characterized as evidence that investors reward good performance by reducing outflows rather than punish poor performance by increasing outflows. Other issues in O'Neal's analysis, however, lead us to be somewhat skeptical of that conclusion. Namely, O'Neal's results do not hold for risk-adjusted returns or for standard measures of flows.

\section{Data}

Our sample was compiled using investment companies' N-SAR filings with the U.S. Securities and Exchange Commission (SEC) and the CRSP Survivor-Bias-Free U.S. Mutual Fund Database. The SEC requires that all regulated investment companies file two $\mathrm{N}$-SARs each fiscal year, the N-SARA covers the first six months of the investment company's fiscal year, and the N-SARB covers the full fiscal year. We pull all N-SARs from the SEC web site for the calendar years 1997 through 2007. Each N-SAR filing identifies the dollar amounts of purchases, dividend purchases, other purchases, and redemptions for each month covered by the filing. We define net flows as investor purchases minus investor redemptions divided by the size of the fund at the beginning of the month. 3 Inflows are investor purchases divided by fund size at the beginning of the month. Outflows are sales divided by fund size at the beginning of the month.4

We utilize the CRSP database for fund returns. We estimate abnormal returns using the Fama-FrenchCarhart four-factor model.5 Factor loadings are estimated every month, for each fund, using the prior 36 months' returns.

Matching the N-SAR filings with CRSP is not a trivial undertaking. Fund's N-SAR filings do not have a unique and consistent identifier through time. This forces us to manually compare various fund identifiers on each N-SAR to create a series of N-SAR filings for each fund. Once this was accomplished, we matched the N-SAR time series to CRSP by manually comparing fund and family names across the two databases. Finally, to ensure the accuracy of our matching procedure, we compare the net asset value reported on the $\mathrm{N}-\mathrm{SAR}$ filing with that in the CRSP database.

We eliminate observations that appear to contain data entry errors. Specifically, we eliminate observations where the net flow, inflow or outflow is greater than $50 \%$ of fund assets. 6 Finally, we 
remove all funds that are not actively managed domestic equity funds. This results in a sample of 88,910 fund-month observations from 3,214 funds from April 1997 through December 2007.7

Table 1 reports descriptive statistics for returns and flows for our sample of domestic equity funds. As might be expected, mean and median raw quarterly returns (equal to $5.7 \%$ and $3.1 \%$, respectively) exceed the four-factor adjusted returns, which are essentially zero. Perhaps more interesting are the results on fund flows. The average monthly net flow is $-0.02 \%$, while the average inflow is $6.83 \%$, and the average outflow is $6.85 \% .8$ These averages suggest that net flows are small relative to inflows and outflows. Comparing the dollar amounts we see that net flows are roughly an order of magnitude less than both inflows and outflows.

Table 1. Descriptive statistics The sample consists of 3,214 domestic equity mutual funds representing the CRSP Survivor-Bias-Free U.S. Mutual Fund Database and N-SAR filings with the SEC. There are 88,910 fund-month observations for the period April 1997 to December 2007. Panel A presents the descriptive statistics of the fund's quarterly raw and abnormal returns. The abnormal return is the fund's Fama-French-Carhart four-factor adjusted return, where the betas are estimated using a rolling 36-month window. Panel B presents descriptive statistics for the fund's monthly net flow and component flows. Net Flows is the amount of new money invested with the fund minus the amount of money withdrawn from the fund during a month, divided by the fund's total net assets at the beginning of the month. Inflow is the amount of new money invested with the fund over the month, divided by the fund's total net assets at the beginning of the month. Outflow is the amount of money withdrawn from the fund over the month, divided by the fund's total net assets at the beginning of the month.

\section{Mean Median Maximum 75th Percentile 25th Percentile Minimum SD}

Panel A: Descriptive statistics for raw and abnormal returns

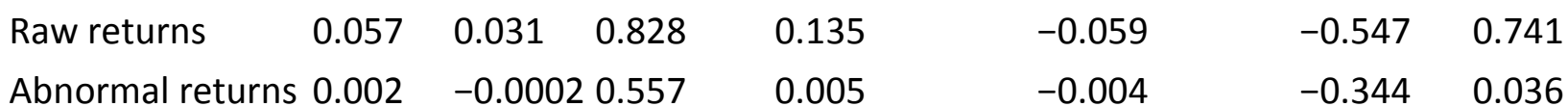

Panel B: Descriptive statistics for dollar net flows inflows and outflows

$\begin{array}{llllllll}\text { Net flows (1,000s) } & 2,073 & -284 & 470,114 & 3,239 & -4,110 & -383,259 & 37,391 \\ \text { Inflow (1,000s) } & 28,661 & 6,806 & 548,185 & 25,327 & 1,867 & 0 & 59,973 \\ \text { Outflow (1,000s) } & 26,588 & 7,689 & 464,983 & 25,291 & 2,408 & 0 & 51,950\end{array}$

Panel C: Descriptive statistics for net flows inflows and outflows

\begin{tabular}{|c|c|c|c|c|c|c|c|}
\hline Net flows & -0.0002 & -0.003 & 0.491 & 0.018 & -0.021 & -0.497 & 0.073 \\
\hline Inflow & 0.0683 & 0.035 & 0.500 & 0.083 & 0.015 & 0 & 0.086 \\
\hline Outflow & 0.0685 & 0.036 & 0.500 & 0.079 & 0.019 & 0 & 0.084 \\
\hline
\end{tabular}

\section{Empirical results}

\subsection{Unconditional analysis}

The first step in our analysis is to examine the performance net flow relation at the monthly frequency. We repeat the analysis of Sirri and Tufano (1998, figure 1) by dividing funds into 20 groups based on their four-factor adjusted return, and calculate the mean net flow for the subsequent month (see 
Figure 1). The net flow results for the best performing funds are consistent with those of Sirri and Tufano (1998) - there is a large jump in net flows for the best performing funds. This is consistent with the long-held belief that the performance net flow relation is asymmetric. What is different about our Figure 1 relative to Sirri and Tufano's figure 1, is that our net flows display a rather consistent decline as performance degrades from the 19th performance bucket to the second performance bucket, whereas net flows are relatively constant in Sirri and Tufano's sample from the first performance bucket to the 13th performance bucket. More notably, however, mean net flows drop dramatically in our sample for the worst performing funds, whereas there is no such drop in net flows in the Sirri and Tufano sample.9 We interpret the results in Figure 1 as suggesting that net flows respond to performance over the broad range of performance, but are particularly sensitive to both very good, and very bad performance. However, we are able to replicate much more closely Sirri and Tufano's (1998) figure 1, when we limit our sample to a period of generally increasing net flows (unreported).

\section{Figure 1}

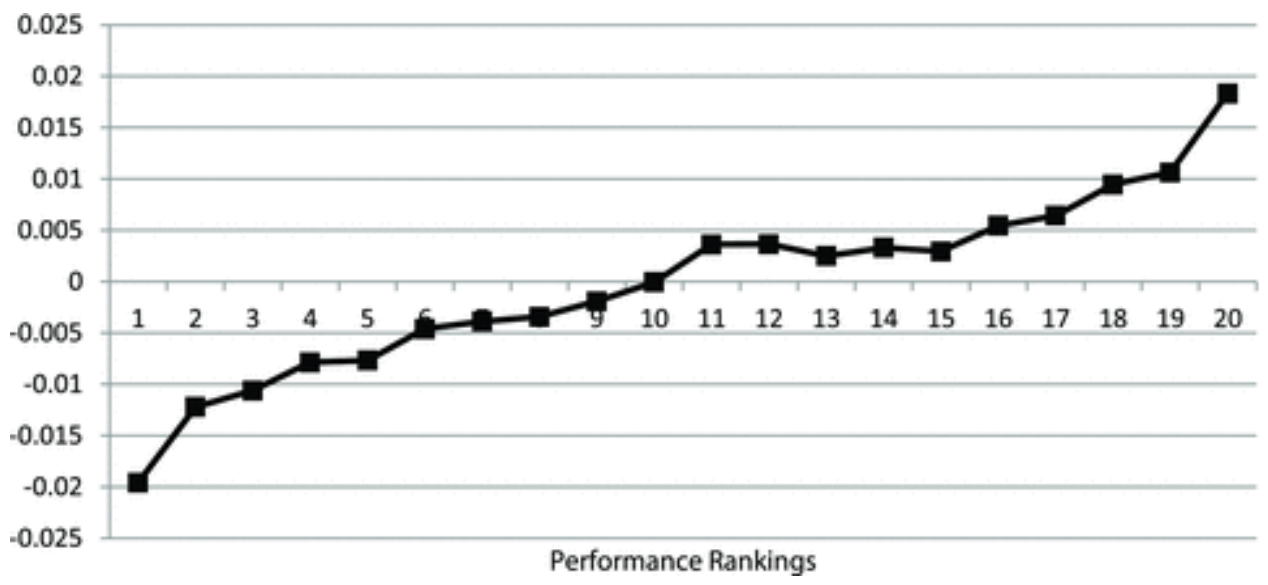

Performance flow relation Each month, mutual funds were ranked among 20 groups based on their monthly performance. We report the mean net flow for each group over the subsequent month.

\subsection{Multivariate analysis of net flows}

To conduct a more formal evaluation of the nonlinearity in monthly flows, we examine the performance net flow relation in a regression model. Following Sirri and Tufano (1998) we measure performance using fractile rankings. Each month, we rank funds based on their prior quarter fourfactor adjusted performance, ranking funds from zero for the worst performing fund to one for the best performing fund. We then spread each fund's performance ranking across terciles, worst performance, middle performance and best performance, and estimate a piecewise linear regression.10 What this means is that if a fund has a performance ranking of 0.85 , then worst performance is 0.33 , middle performance is 0.33 , and best performance is 0.19 . A fund with a performance ranking of 0.4 would have a worst performance of 0.33 , a middle performance of 0.07 , and a best performance of 0.00 .

Following Sirri and Tufano (1998), we control for fund expenses, $12 \mathrm{~b}-1$ fees, and the standard deviation of the funds' monthly (abnormal) return over the prior 12 months. We also control for trading fees associated with entering and leaving the fund, as it seems likely that frictions associated with trading may affect flows. Rather than using an indicator variable capturing the presence of a fee (front-end loads, contingent deferred sales charges, and redemption fees), we compute effective measures for each type of trading fee. We calculate our effective fee measure by dividing the total dollar amount 
collected under the fee by the total amount of trading that could be subjected to the fee.11 For example, to calculate our measure of effective front-end loads we divide the dollar amount of frontend loads collected by the total amount of inflows during the six-month reporting period.12 Using this methodology, we calculate effective front-end loads, effective back-end loads, and effective redemption fees. Also, Del Guercio and Tkac (2002), Coval and Stafford (2007), and Jaiprakash and Kumar (2009) find meaningful persistence in mutual fund net flows. Accordingly, we control for lagged flows in our analysis.13 Finally, while we conduct both Fama-MacBeth and pooled ordinary least squares (OLS) analysis, we only report our Fama-MacBeth findings, as Coval and Stafford (2007) find that the Fama-MacBeth coefficient estimates are more precise than pooled OLS estimates. We note that our pooled OLS results are statistically, and qualitatively similar to our Fama-MacBeth results.

We present the results of our monthly net flow analysis in Table 2. The results confirm those in Figure 1. Consistent with prior research, we find that net flows are sensitive to performance for the best performing funds. For funds in the middle tercile of performance, there is a positive relation between performance and flows, but the relation is only marginally significant. Our findings with respect to poorly performing funds are likely the most interesting, however. We find that there is a significant positive relation between performance and net flows for the worst performing funds, implying that poorly performing funds experience lower net flows. While prior research on the performance net flow relation has documented a much stronger reaction to performance among the best performing funds than among the worst performing funds, we find no evidence that net flows respond more aggressively to good performance than to bad in unreported tests. However, if we limit our sample to a period of generally increasing net flows (unreported), we find evidence that net flows respond more aggressively to good performance than poor performance, which is consistent with prior studies. This suggests that, potentially the asymmetric net flow response to performance is an artifact of the samples examined.

Table 2. The relation between performance and net flows This table presents our Fama-MacBeth analysis of the relation between fund performance and the subsequent net flows. The dependent variable is Net Flow, which is the amount of new money invested in the fund minus the amount of money withdrawn from the fund over a month, divided by the size of the fund at the beginning of the month. We measure prior quarter performance using the fractile ranking of the funds Fama-FrenchCarhart four-factor adjusted returns, where the adjustment is based on rolling betas estimates over the prior 36 months. Worst performance tercile is defined as Min (Rank, 0.33). Middle performance tercile is defined as Min (0.33, Rank - Worst). Best performance tercile is defined as Rank - Middle - Worst. LnSize is the natural log of the fund's total net asset at the beginning of the month. StdRet is the standard deviation of the fund's abnormal monthly returns over the previous 12 months. ExpenseRatio is the expense ratio over the six-month N-SAR reporting period. EffectiveFrontLoad is the money that the fund collected from the front-end load over the six-month reporting period, divided by the amount of new money flowing into the fund over the same six-month reporting period.

EffectiveRedemptionFee is the money generated from the fund's redemption fee over the six-month reporting period, divided by the amount of money withdrawn from the fund during the same sixmonth reporting period. EffectiveCDSC is the money collected from the fund's contingent deferred sales charges over the six-month reporting period, divided by the amount of money withdrawn from the fund during the same six-month reporting period. $12 b-1$ Fee is the money generated for the fund from $12 b-1$ fees over the six-month reporting period, divided by the size of the fund at the time of the $\mathrm{N}$-SAR filing. Lagged Net flows represent lags 1 through 12 of the dependent variable. $t$-Statistics are in parentheses. 
Intercept $-0.005^{* *}$

Worst performance tercile

$0.021 * * *$

Middle performance tercile $0.005^{*}$

Best performance tercile

$0.028 * * *$

LnSize

StdRet

ExpenseRatio

$-0.202 * * *$

EffectiveFrontLoad

$-0.009$

EffectiveRedemptionFee

EffectiveCDSC

12b-1 Fee

0.018

(0.13)

Lagged net flows included? Yes

Adjusted $R^{2}$

0.4846

$* * *, * *, *$ indicate statistical significance at the $0.01,0.05$ and 0.10 level, respectively.

\subsection{Multivariate analysis of gross flows}

Having examined the relation between performance and net flows, we assess the performance of gross flow relations. O'Neal (2004) finds evidence that a portion of mutual fund inflows and outflows are related to the contemporaneous flow in the opposite direction. Additionally, recent research suggests that traders can quickly move in and out of a mutual fund, with potentially meaningful effects on the observed flow patterns (Chalmers, Edelen and Kadlec, 2001; Greene and Hodges, 2002; Zitzewitz, 2006).14 Accordingly, we control for flows in the opposite direction, when we examine the relation between performance and gross flows. Our results are reported in Table 3.

Table 3. The relation between performance and gross flows This table presents our Fama-MacBeth analysis of the relation between performance and gross flow (outflow and inflow). The dependent variable in column 1 is Outflow, which is the amount of money withdrawn from the fund over a month, divided by the size of the fund at the beginning of the month. The dependent variable in column 2 is Inflow, which is the amount of new money invested with the fund over the month, divided by the size 
of the fund at the beginning of the month. We measure prior quarter performance using the fractile ranking of the funds Fama-French-Carhart four-factor adjusted returns, where the adjustment is based on rolling betas estimates over the prior 36 months. Worst performance tercile is defined as Min (Rank, 0.33). Middle performance tercile is defined as Min (0.33, Rank - Worst). Best performance tercile is defined as Rank - Middle - Worst. LnSize is the natural log of the fund's total net asset at the beginning of the month. StdRet is the standard deviation of the fund's abnormal monthly returns over the previous 12 months. ExpenseRatio is the expense ratio over the six-month N-SAR reporting period. EffectiveFrontLoad is the money that the fund collected from the front-end load over the six-month reporting period, divided by the amount of new money flowing into the fund over the same six-month reporting period. EffectiveRedemptionFee is the money generated from the fund's redemption fee over the six-month reporting period, divided by the amount of money withdrawn from the fund during the same six-month reporting period. EffectiveCDSC is the money collected from the fund's contingent deferred sales charges over the six-month reporting period, divided by the amount of money withdrawn from the fund during the same six-month reporting period. $12 b$ - 1 Fee is the money generated for the fund from $12 b-1$ fees over the six-month reporting period, divided by the size of the fund at the time of the N-SAR filing. Lagged Outflows and Lagged Inflows represent lags 1 through 12 of the dependent variables. Contemporaneous Inflow and Contemporaneous Outflow represent the column 2 and 1 dependent variables, respectively. $t$-Statistics are in parentheses.

\begin{tabular}{|c|c|c|}
\hline Intercept & $\begin{array}{l}0.009 * * * \\
(6.54)\end{array}$ & $\begin{array}{l}-0.0003 \\
(-0.23)\end{array}$ \\
\hline Worst performance tercile & $-0.021 * * *$ & $0.012 * * *$ \\
\hline & $(-7.93)$ & $(4.24)$ \\
\hline Middle performance tercile & $-0.004^{*}$ & 0.001 \\
\hline & $(-1.85)$ & $(0.51)$ \\
\hline Best performance tercile & $-0.010 * * *$ & $0.023 * * *$ \\
\hline & $(-3.86)$ & $(6.78)$ \\
\hline LnSize & -0.0001 & $-0.0004 * * *$ \\
\hline & $(-1.48)$ & $(-4.27)$ \\
\hline StdRet & 0.002 & $-0.057 * *$ \\
\hline & $(0.10)$ & $(-2.49)$ \\
\hline ExpenseRatio & $0.149 * *$ & $-0.167 * * *$ \\
\hline & $(2.49)$ & $(-3.14)$ \\
\hline EffectiveFrontLoad & $-0.057 * * *$ & -0.023 \\
\hline & $(-4.12)$ & $(-1.47)$ \\
\hline EffectiveRedemptionFee & $64.720 *$ & 11.660 \\
\hline & $(1.81)$ & $(0.23)$ \\
\hline EffectiveCDSC & $-0.348 * * *$ & $0.165^{*}$ \\
\hline & $(-4.68)$ & $(1.82)$ \\
\hline $12 b-1 \mathrm{Fee}$ & -0.060 & 0.033 \\
\hline & $(-0.46)$ & $(0.34)$ \\
\hline
\end{tabular}




$\begin{array}{lll} & \begin{array}{l}\text { Outflow } \\ \text { Contemporaneous inflow }\end{array} & \begin{array}{l}\text { Inflow } \\ \left(17.105^{* * *}\right.\end{array} \\ & & \\ \text { Contemporaneous outflow } & & \begin{array}{l}0.206^{* * *} \\ (15.50)\end{array} \\ \text { Lagged outflows included? } & \text { Yes } & \text { No } \\ \text { Lagged inflows included? } & \text { No } & \text { Yes } \\ \text { Adjusted } R^{2} & 0.6854 & 0.7096\end{array}$

$* * *, * *, *$ indicate statistical significance at the $0.01,0.05$ and 0.10 level, respectively.

The first thing to note in column 1 of Table 3 is that, unlike previous research, we document a relation between relative performance and outflows. In particular, we find that as performance declines, current investors punish poorly performing funds with larger withdrawals. Our coefficient estimate for the worst performance tercile implies that a fund going from the 33rd percentile to the lowest percentile would suffer an almost $9 \%$ increase in outflows (relative to the average fund's monthly outflows). 15 It is important to remember that this is the flow for one month. Given the persistence in flows, the total effect will be much larger over time. This result stands in stark contrast to prior examinations of the performance outflow relation; as mentioned earlier, Bergstresser and Poterba (2002), Johnson (2007), and Ivkovic and Weisbenner (2009) all find no relation between relative performance and outflows. This result also contradicts Johnson's (2007) conclusion that current investors stop monitoring fund managers once they have invested in the fund.

Also of interest are investors' reactions to good performance. We can see that among the best performing funds there is a negative relation between performance and outflows. This implies that current investors withdraw less from better performing funds. However, we find that the outflow response to performance is asymmetric with the response to poor performance being stronger than the response to good performance.16

Results on our control variables largely are consistent with expectations. In particular, outflows increase with expense ratios (the cost of staying in a fund) and decrease with fund transactions costs (the expense to get out of the fund). Like O'Neal (2004), we find that contemporaneous inflows are an important determinant of fund outflows.

We also examine the determinants of fund inflows. Our results are threefold. First, we find that among the best performing funds there is a positive relation between performance and inflows, which is consistent with prior research. Second, and more surprisingly, we also find that there is a significant positive relation between performance and inflows for the worst performing funds-investors invest less in poorly performing funds. This result suggests that potential investors also are reacting to poor performance. Third, we find that there is a statistically significant difference between the coefficients for the best and worst performing funds ( $p$-value $=0.015)$. Like outflows, inflows respond asymmetrically to fund performance.

Results on our control variables are generally consistent with our expectations. As was the case with outflows, the concurrent cross flow is an important determinant of inflows. Additionally, funds with higher expense ratios experience lower levels of inflows. More surprisingly, though, we find some (albeit weak) evidence that higher deferred sales charges increase fund inflows. While this result may 
appear surprising, one possibility is that loads associated with leaving a fund serve to screen out shortterm investors (e.g., Chordia, 1996; Nanda, Narayanan and Warther, 2000). Johnson (2004) finds that the liquidity needs of short-term investors represent a significant cost to long-term investors. Perhaps, then, our finding reflects long-term investors rationally choosing funds with higher transaction fees, and fewer short-term investors.17

The outflow and inflow results are represented graphically in Figure 2 . The horizontal axis is the performance fractile ranking from zero to one while the vertical axis captures gross flow scaled by the expected flow to a fund with average performance. Note that the worst performing funds (lowest percentile) experience outflows which are more than $12.4 \%$ higher than the average fund, while the best performing (highest percentile) fund's outflows are $6.6 \%$ less than outflows at the average fund. Among the tercile of worst performing funds, going from the 33rd percentile to the lowest percentile of performance implies outflows increase by $11.4 \%$ of the average fund's outflows.

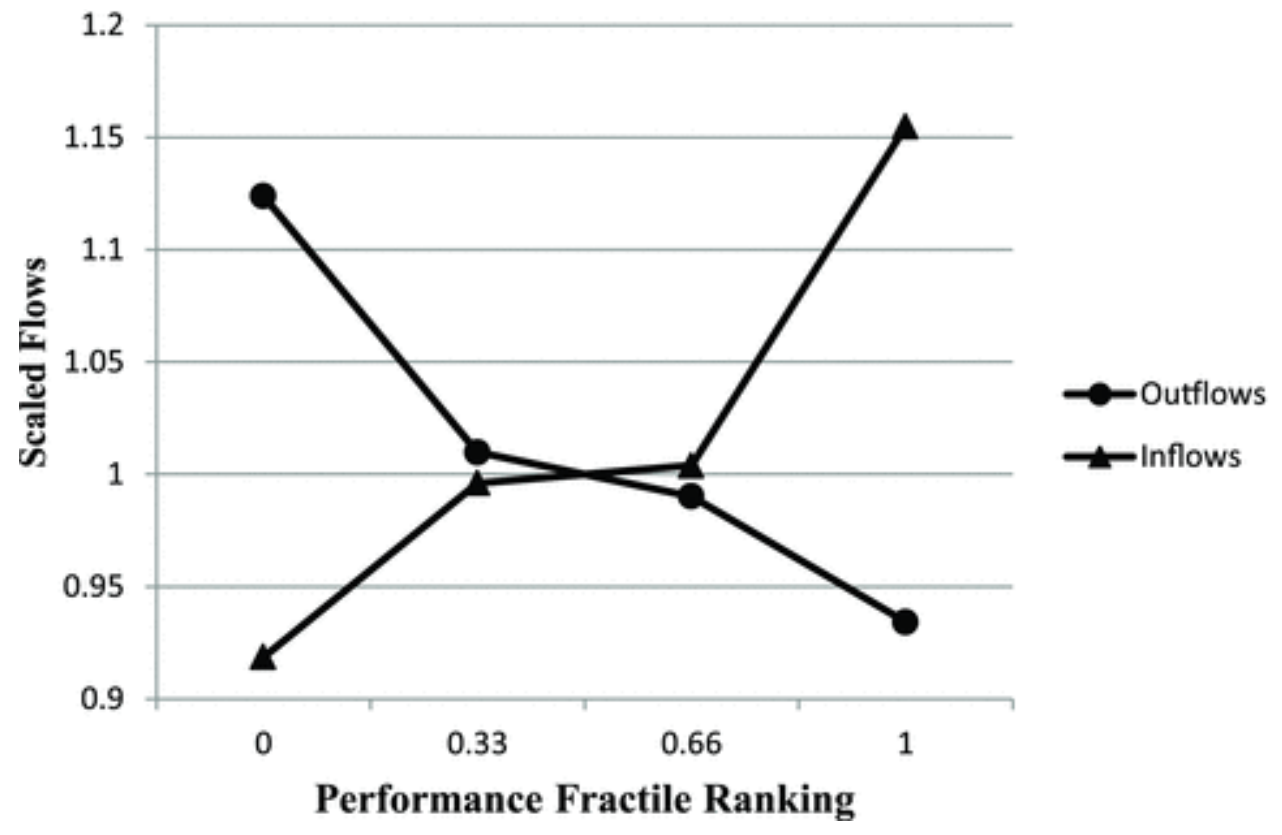

Figure 2

Estimated performance gross flow relation This figure depicts the relation between performance and mutual fund gross flows. Gross flows are estimated using the coefficients reported in Table 3; all nonperformance variables are set equal to their mean while performance changes from 0 to 1. Estimated gross flows are scaled by their respective means.

A similar, but somewhat less pronounced pattern exists for inflows. The worst performing funds experience inflows which are $91.9 \%$ of the mean fund's inflows, while the best performing funds experience inflows that are $15.5 \%$ greater than the mean funds. Among the best performing funds, moving from the 66th percentile to the 100th percentile implies an increase in inflows from $100.4 \%$ of the mean fund's inflows to $115.5 \%$. Like outflows, the relation between performance and inflows appears to be economically, as well as statistically significant.

Overall, our analysis shows that investors respond to both good and bad performance. Current investors increase their withdrawals when funds do poorly. Additionally, current investors decrease their withdrawals for those funds that have done well. The outflow response to good and bad performance is asymmetric, with current investors responding more to bad performance than to good 
performance. Our results for inflows, are similar, but in the opposite direction. Inflows respond asymmetrically to good and bad performance, but the response to good performance is stronger than the response to bad performance. Finally, net flows respond symmetrically to performance.18

\section{Additional analysis}

In this section, we first discuss the role of participation costs in driving the nonlinear performance net flow relation. Next, we provide evidence on investor reactions to fund performance at different time intervals and flow periodicity. Finally, we reconsider our analysis using an alternative measure of performance.

\subsection{Evidence on participation costs}

Huang, Wei and Yan (2007) suggest that new investors drive the nonlinearity between performance and net flows. In their model, new investors consider performance as an indicator of managerial quality, but participation costs mitigate the response to any performance other than the very best, thus driving the observed nonlinear relation between performance and net flows. They argue that the response to moderate performance should be greater for funds with lower participation costs, and they find evidence consistent with this explanation.

However, Huang, Wei and Yan (2007) do not analyze gross flows - they can only rely on net flows to draw conclusions about new investor responses to fund performance. Because we have inflow data, we are able to make a more direct test of their theory. Inflows are a better measure of new investor activity than net flows because, unlike net flows, inflows are not influenced by the redemption behavior of existing investors. We use three of Huang, Wei and Yan's (2007) proxies for low participation costs: (1) expense ratios plus one-seventh of the front-end load, (2) fund family size, and (3) the number of fund styles offered by the fund family. We examine the relation between performance and inflows as a function of participation costs in Table 4. Regardless of the choice of participation cost proxy, we find no evidence that participation costs affect the performance inflow relation.

Table 4. The effect of participation costs on the performance inflow relation This table presents our Fama-MacBeth analysis of the effect of participation cost on the performance inflow relation. The dependent variable is Inflow, which is the amount of new money invested in the fund over a month, divided by the size of the fund at the beginning of the month. The independent variables of interest are the performance terciles, and the interaction of the performance terciles with the Huang, Wei and Yan (2007) low participation cost proxies. We measure prior quarter performance using the fractile ranking of the funds Fama-French-Carhart four-factor adjusted returns, where the adjustment is based on rolling betas estimates over the prior 36 months. Worst performance tercile is defined as Min (Rank, 0.33). Middle performance tercile is defined as Min (0.33, Rank - Worst). Best performance tercile is defined as Rank - Middle - Worst. Following Huang, Wei and Yan (2007), we use Fees, Family Size, and Family Styles to simulate low participation costs. Fees is an indicator set equal to 1 if the expense ratio plus one-seventh of the front-end load is above the median fee level. Family Size is an indicator set equal to 1 if the fund's size is greater than the median. Family Styles is an indicator that is set equal to 1 if the number of investment styles the fund's family offers is greater than the median number. Contemporaneous Outflows are the fund's outflows for the same month as the inflows. Lagged Inflows represent lags 1 through 12 of the dependent variables. The other independent variables are the same as in Table 3. $t$-Statistics are in parentheses. 


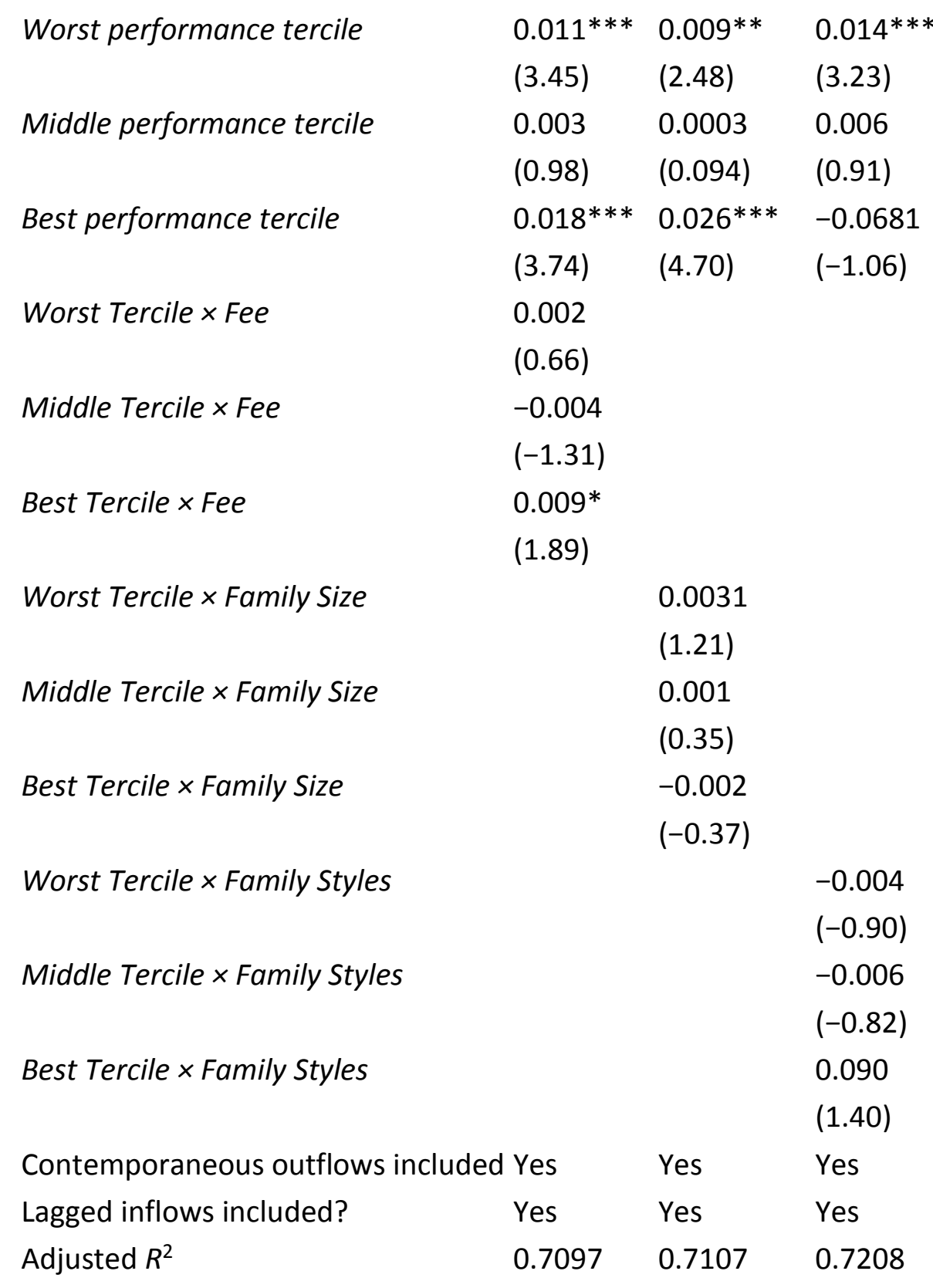

$* * *, * *, *$ indicate statistical significance at the $0.01,0.05$ and 0.10 level, respectively.

\subsection{Evidence from other performance and flow windows}

One potential concern is that our results may not be generalizable; that is our result may only be descriptive of investors who evaluate quarterly performance. We repeat all of our analysis using semiannual and annual performance. For brevity, we leave the results untabulated.19 Even at longer performance evaluation windows, outflows and inflows demonstrate the same asymmetry discussed in Table 3. Investors punish poor performance by increasing outflows (and decreasing inflows) and reward good performance by reducing outflows (and increasing inflows). Thus, we conclude that our results are not driven by our choice of a quarterly performance evaluation period. 
Additionally, we repeat all of our analysis using quarterly performance and quarterly flows instead of quarterly performance and monthly flows. We report our quarterly outflow and inflow results in Table 5. The results mirror those from our monthly analysis. We continue to see that current investors punish poor performance by withdrawing money and reward good performance by reducing their withdrawals from funds that have done well. Similarly, we see that current and potential investors reward funds for good performance by increasing their purchases of fund shares while at the same time punishing poor performance by reducing their purchases.

Table 5. The relation between performance and quarterly gross flows This table presents our FamaMacBeth analysis of the relation between quarterly performance and quarterly gross flow (outflow and inflow). The dependent variable in column 1 is Outflow, which is the amount of money withdrawn from the fund over a quarter, divided by the size of the fund at the beginning of the quarter. The dependent variable in column 2 is Inflow, which is the amount of new money invested with the fund over the quarter, divided by the size of the fund at the beginning of the quarter. We measure prior quarter performance using the fractile ranking of the funds Fama-French-Carhart four-factor adjusted returns, where the adjustment is based on rolling betas estimates over the prior 36 months. Worst performance tercile is defined as Min (Rank, 0.33). Middle performance tercile is defined as Min (0.33, Rank - Worst). Best performance tercile is defined as Rank - Middle - Worst. LnSize is the natural log of the fund's total net asset at the beginning of the quarter. StdRet is the standard deviation of the fund's abnormal monthly returns over the previous 12 months. ExpenseRatio is the expense ratio over the sixmonth N-SAR reporting period. EffectiveFrontLoad is the money that the fund collected from the frontend load over the six-month reporting period, divided by the amount of new money flowing into the fund over the same six-month reporting period. EffectiveRedemptionFee is the money generated from the fund's redemption fee over the six-month reporting period, divided by the amount of money withdrawn from the fund during the same six-month reporting period. EffectiveCDSC is the money collected from the fund's contingent deferred sales charges over the six-month reporting period, divided by the amount of money withdrawn from the fund during the same six-month reporting period. $12 b-1$ Fee is the money generated for the fund from $12 \mathrm{~b}-1$ fees over the six-month reporting period, divided by the size of the fund at the time of the N-SAR filing. Lagged Outflows and Inflows represent lags 1 through 4 of the dependent variables. $t$-Statistics are in parentheses.

$\begin{array}{lll} & \text { Outflows } & \text { Inflows } \\ \text { Intercept } & 0.039^{* * *} & -0.002 \\ & (5.37) & (-0.21) \\ \text { Worst performance tercile } & -0.067^{* * *} & 0.042^{* * *} \\ & (-4.10) & (3.45) \\ \text { Middle performance tercile } & -0.012 & 0.022^{*} \\ & (-1.03) & (1.86) \\ \text { Best performance tercile } & -0.024^{*} & 0.075^{* * *} \\ & (-1.79) & (3.89) \\ \text { InSize } & -0.001 & -0.001^{* *} \\ & (-1.45) & (-2.61) \\ \text { StdRet } & -0.092 & -0.136 \\ & (-0.84) & (-1.39)\end{array}$




$\begin{array}{lll} & \text { Outflows } & \text { Inflows } \\ \text { ExpenseRatio } & 0.140 & -0.988^{* * *} \\ & (0.48) & (-3.03) \\ \text { EffectiveFrontLoad } & -0.177^{* *} & -0.043 \\ & (-2.29) & (-0.57) \\ \text { EffectiveRedemptionFee } & 73.180 & -47.210 \\ & (1.13) & (-1.10) \\ \text { EffectiveCDSC } & -1.802^{* * *} & 0.650 \\ & (-4.46) & (1.37) \\ \text { 12b-1 Fee } & 1.124^{*} & 0.793 \\ & (1.86) & (1.45) \\ \text { Contemporaneous inflows } & 0.240^{* * *} & \\ \text { Contemporaneous outflows } & & \\ & (12.80) & 0.267^{* * *} \\ \text { Lagged outflows included? } & \text { Yes } & (11.00) \\ \text { Lagged inflows included? } & \text { No } & \text { Yes } \\ \text { Adjusted } R^{2} & 0.7248 & 0.7233 \\ & & \\ & & \\ & & \end{array}$

$* * *, * *, *$ indicate statistical significance at the $0.01,0.05$ and 0.10 level, respectively.

Column 1 of Table 5 also shows that the response of outflows to the worst performance is greater than the response of outflows to good performance. We see that the coefficient on the worst performance tercile is -0.067 and the coefficient on the best performance tercile is -0.024 . The difference is statistically significant ( $p$-value $=0.041$ ). Again, this evidence runs contrary to the notion that current investors are essentially indifferent to poor performance.

We note that there is some difference between these results from our earlier results with respect to inflows. Like our earlier results, inflows react to both good and bad performance. What is different, however, is that the reaction is no longer obviously asymmetric. The coefficient for the best performing funds is 0.075 while the coefficient for the worst performing funds is only 0.042 . The difference is not statistically significant ( $p$-value $=0.162)$.

\subsection{Evidence using style-adjusted returns}

We compare a fund's performance to all other funds in our sample throughout our study. It could be that investors are more interested in how a fund performs relative to other funds with the same style. To explore this possibility we rank each fund's quarterly performance against only those funds with the same self-reported style, instead of against all the funds in our sample. The results are presented in Table 6.

Table 6. Style ranked performance This table presents our Fama-MacBeth analysis of the relation between quarterly performance and quarterly gross flow (outflow and inflow). The dependent variable in column 2 is Outflow, which is the amount of money withdrawn from the fund over a quarter, divided by the size of the fund at the beginning of the quarter. The dependent variable in column 3 is Inflow, 
which is the amount of new money invested with the fund over the quarter, divided by the size of the fund at the beginning of the quarter. We measure prior quarter performance using the fractile ranking of the funds Fama-French-Carhart four-factor adjusted returns, where the adjustment is based on rolling betas estimates over the prior 36 months. Each fund is ranked against all other funds within its investment strategy. Worst Style-performance tercile is defined as Min (Rank, 0.33). Middle Styleperformance tercile is defined as Min (0.33, Rank - Worst). Best Style-performance tercile is defined as Rank - Middle - Worst. LnSize is the natural log of the fund's total net asset at the beginning of the quarter. StdRet is the standard deviation of the fund's abnormal monthly returns over the previous 12 months. ExpenseRatio is the expense ratio over the six-month N-SAR reporting period.

EffectiveFrontLoad is the money that the fund collected from the front-end load over the six-month reporting period, divided by the amount of new money flowing into the fund over the same six-month reporting period. EffectiveRedemptionFee is the money generated from the fund's redemption fee over the six-month reporting period, divided by the amount of money withdrawn from the fund during the same six-month reporting period. EffectiveCDSC is the money collected from the fund's contingent deferred sales charges over the six-month reporting period, divided by the amount of money withdrawn from the fund during the same six-month reporting period. $12 b-1$ Fee is the money generated for the fund from 12b-1 fees over the six-month reporting period, divided by the size of the fund at the time of the N-SAR filing. Lagged Outflows and Inflows represent lags 1 through 4 of the dependent variables. $t$-Statistics are in parentheses.

\begin{tabular}{|c|c|c|c|}
\hline & Net flow & Outflow & Inflow \\
\hline \multirow[t]{2}{*}{ Intercept } & $-0.005^{* * *}$ & $0.007^{* * *}$ & -0.0003 \\
\hline & $(-3.69)$ & $(5.62)$ & $(-0.22)$ \\
\hline \multirow[t]{2}{*}{ Worst Style-performance tercile } & $0.020 * * *$ & $-0.016 * * *$ & $0.009 * * *$ \\
\hline & $(5.91)$ & $(-5.86)$ & $(3.66)$ \\
\hline \multirow[t]{2}{*}{ Middle Style-performance tercile } & $0.006 * *$ & $-0.006 * * *$ & 0.003 \\
\hline & $(2.59)$ & $(-3.15)$ & $(1.61)$ \\
\hline \multirow[t]{2}{*}{ Best Style-performance tercile } & $0.016 * * *$ & $-0.006 * * *$ & $0.013^{* * *}$ \\
\hline & $(5.87)$ & $(-2.93)$ & (5.69) \\
\hline \multirow[t]{2}{*}{ LnSize } & $-0.0004^{* * *}$ & -0.0001 & $-0.0004 * * *$ \\
\hline & $(-3.64)$ & $(-0.89)$ & $(-4.47)$ \\
\hline \multirow[t]{2}{*}{ StdRet } & -0.014 & 0.006 & $-0.036^{*}$ \\
\hline & $(-0.57)$ & $(0.27)$ & $(-1.69)$ \\
\hline \multirow[t]{2}{*}{ ExpenseRatio } & $-0.187^{* * *}$ & $0.161 * * *$ & $-0.150 * * *$ \\
\hline & $(-3.07)$ & $(2.69)$ & $(-2.83)$ \\
\hline \multirow[t]{2}{*}{ EffectiveFrontLoad } & -0.008 & $-0.062 * * *$ & -0.026 \\
\hline & $(-0.42)$ & $(-4.42)$ & $(-1.64)$ \\
\hline \multirow[t]{2}{*}{ EffectiveRedemptionFee } & -33.101 & $76.678^{*}$ & 9.481 \\
\hline & $(-0.93)$ & $(1.78)$ & $(0.21)$ \\
\hline \multirow[t]{2}{*}{ EffectiveCDSC } & $0.359 * * *$ & $-0.352 * * *$ & $0.169 *$ \\
\hline & (3.83) & $(-4.88)$ & $(1.83)$ \\
\hline $12 b-1 \mathrm{Fee}$ & -0.020 & -0.068 & 0.0004 \\
\hline
\end{tabular}




\section{Net flow Outflow Inflow}

Contemporaneous inflows

Contemporaneous outflows

Lagged net flows included?

Lagged outflows included?

Lagged inflows included?

Adjusted $R^{2}$
$(-0.14)$

$(-0.52)$

$0.182 * * *$

$0.204 * * *$

$\begin{array}{lll}\text { Yes } & \text { No } & \text { No } \\ \text { No } & \text { Yes } & \text { No } \\ \text { No } & \text { No } & \text { Yes }\end{array}$

0.4820

0.6845

0.7082

$* * *, * *, *$ indicate statistical significance at the $0.01,0.05$ and 0.10 level, respectively.

Those results are consistent with those reported earlier. Similar to the results presented in Table 2 we find that net flows respond to both the best and worst performance. We again fail to find evidence of an asymmetric response to performance.

Examining the relation between gross flows and relative style performance reveals results similar to those presented in Table 3. We find that outflows are more sensitive to the worst performance than to the best performance. While inflows are sensitive to both the worst and best performance, unlike in Table 3, we find no evidence that inflows are more sensitive to the best performance. In general the results presented in Table 6 support our earlier findings.

\section{Conclusion}

One of the best documented empirical regularities in mutual fund research is the nonlinear relation between past performance and net flows. We re-examine that relation, as well as the relations between performance and the two components of net flows (outflows and inflows) using a large sample of equity funds over a period that includes both increasing and decreasing net flows.

We find that net flows respond symmetrically to performance. Investors respond to both good and bad performance in a similar way. This result runs contrary to current research, which suggests that net flows respond to good performance, but not to bad performance.

Second, we find that outflows respond to performance, as well. Specifically, current investors withdraw more from poorly performing funds, while they withdraw less from funds with better performance. While outflows respond to both good and bad performance, the response is asymmetric. Outflows more likely increase as a result of poor performance, than decrease as a result of good performance.

Finally, we find that inflows respond to both good and bad performance. Previous research has suggested that while inflows are responsive to good performance, they are not affected by bad performance. We find that inflows are indeed affected by bad performance. Like outflows, however, the response of inflows to good and bad performance is asymmetric. Increases in inflows resulting from good performance are greater than the reductions in performance stemming from poor performance. 


\section{Footnotes}

1 Berk and Tonks (2007), in explaining persistence in poor fund performance, embrace the assumption of heterogeneity in investor sensitivity to poor performance. Their argument is that investors differ in their sensitivities to poor fund performance. When low-skill managers produce inferior performance, investors with high performance sensitivities leave the fund; the remaining investors are largely insensitive to performance. When the low-quality manager produces inferior performance again, there is no response from existing investors, as only performance-insensitive investors remain in the fund. Christoffersen and Musto (2002) make a similar argument.

2 While these studies find no evidence of a relation between relative performance and outflows they do find some evidence that outflows are tax motivated.

3 We note that the correlation between our net flow measure, and the Sirri and Tufano (1998) net flow proxy is 0.501 , in our sample. Sirri and Tufano (1998) calculate net flows as $\left\{\right.$TNAA$_{t}-\left[\right.$ TNA $_{t-1} \times(1+$ Return $\left.\left.\left._{t}\right)\right]\right\} /$ TNA $_{t-1}$.

4 This is the same measure of gross flows used by Bergstresser and Poterba (2002), O'Neal (2004), Johnson (2007), and Christoffersen, Evans and Musto (2007).

5 The Fama-French three factors and the momentum factor were downloaded from Kenneth French's web site: http://mba.tuck.dartmouth.edu/pages/faculty/ken.french/data_library.html.

6 Additionally, we drop observations with an effective expense ratio, a redemption fee, or a 12b-1 fee above $2 \%$, or an effective front-end load, or deferred sales fee above $7 \%$.

7 Our sample starts in 1997 because electronic N-SAR filings were not mandatory prior to 1997.

8 Our net flow average is comparable to the Sirri and Tufano (1998) calculated mean (median) net flows of $0.13 \%(0.07 \%)$.

9 The average monthly net flow following performance in the top bucket is slightly more than $1.8 \%$ of fund assets. On an annual basis, this would imply a net flow of approximately $21.6 \%$ of fund assets, consistent with Sirri and Tufano (1998).

10 To make sure our results are not driven by setting our breakpoints at the 33rd and 67th percentiles of performance, we also try several other breakpoint specifications. (e.g., 20-60-20, 10-80-10) and find similar results. Additionally, our results hold when we measure performance using single-factor adjusted returns, as well as raw returns.

11 The N-SAR provides us with the dollar amount of each type of trading fee collected over each sixmonth reporting period.

12 Thus, a particular fund will have the same values for effective fees for six consecutive monthly observations.

13 We do not control for persistence in performance since there is no evidence of equity fund performance persistence in the research. However, there is some evidence on performance persistence in bond funds that has been documented by Polwitoon and Tawatnuntachai (2008).

14 Chalmers, Edelen and Kadlec (2001), Greene and Hodges (2002), and Zitzewitz (2006) use daily flow data from TrimTabs to demonstrate the ability of these traders to systematically transfer wealth from long-term investors to themselves. The TrimTabs data capture flows for a small subset of 
mutual funds (about $12 \%$ of U.S. open-end funds [Zitzewitz (2006)]) over a relatively brief period of time [e.g., Zitzewitz's (2006) sample covers January 1998 to October 2001].

15 The average fund has mean size, all control variables set to their means, and average performance.

16 In unreported tests we compare the outflow response to the worst and best performance. We find that the difference is statistically significant with a $p$-value of 0.0033 .

17 The importance of long-term investors to the performance inflow relation is evident, as the Investment Company Institute (2009) reports that about two-thirds of all mutual fund investments (gross inflows) are made through employer-sponsored retirement plans.

18 One may worry that these results reflect the trading of mutual fund timers. In untabulated tests we explore this issue by removing growth funds from the sample, as these are the domestic funds most likely to be targeted by timers. We find that removing growth funds does not qualitatively change our results.

19 The complete tabulated results are available from the authors on request.

\section{References}

Bergstresser, D. and J. Poterba, 2002. Do after-tax returns affect mutual fund inflows? Journal of Financial Economics 63, 381-414.

Berk, J.B. and R.C. Green, 2004. Mutual fund flows and performance in rational markets, Journal of Political Economy 112, 1269-1295.

Berk, J.B. and I. Tonks, 2007. Return persistence and fund flows in the worst performing mutual funds. Working paper, National Bureau of Economic Research.

Chalmers, J.M.R., R.M. Edelen, and G.B. Kadlec, 2001. On the perils of financial intermediaries setting securities prices: The mutual fund wild card option, The Journal of Finance 56, 2209-2236.

Chevalier, J. and G. Ellison, 1997. Risk taking by mutual funds as a response to incentives, Journal of Political Economy 105, 1167-1200.

Chordia, T., 1996. The structure of mutual fund charges, Journal of Financial Economics 41, 3-39.

Christoffersen, S., R. Evans, and D. Musto, 2007. Fund flows vs. family flows: Evidence from the cross section of brokers. Working paper, University of Pennsylvania .

Christoffersen, S. and D. Musto, 2002. Demand curves and the pricing of money management, The Review of Financial Studies 15, 1499-1524.

Coval, J. and E. Stafford, 2007. Asset fire sales (and purchases) in equity markets, Journal of Financial Economics 86, 479-512.

Del Guercio, D. and P.A. Tkac, 2002. The determinants of the flow of funds of managed portfolios: Mutual funds vs. pension funds, Journal of Financial and Quantitative Analysis 37, 523-557.

Greene, J. and C. Hodges, 2002. The dilution impact of daily fund flows on open-end mutual funds, Journal of Financial Economics 65, 131-158.

Gruber, M.J., 1996. Another puzzle: The growth in actively managed mutual funds. Journal of Finance $51,783-810$.

Huang, J., K.D. Wei, and H. Yan, 2007. Participation costs and the sensitivity of fund flows to past performance, Journal of Finance 62, 1273-1311.

Investment Company Institute, 2009. Research Fundamentals: Characteristics of Mutual Fund Investors, 2008 (Investment Company Institute, Washington, DC ).

Investment Company Institute, 2010. Fact Book (Investment Company Institute, Washington , DC ). 
Ivkovic, Z. and S. Weisbenner, 2009. Individual investor mutual fund flows, Journal of Financial Economics 92, 223-237.

Jaiprakash, P. and R. Kumar, 2009. A close look at the aggregate fund flows and market returns relationship. Working paper, Virginia Tech .

Johnson, W.T., 2004. Predictable investment horizons and wealth transfers among mutual fund shareholders, Journal of Finance 59, 1979-2012.

Johnson, W.T., 2007. Who monitors the mutual fund manager, new or old shareholders? Unpublished working paper, Securities and Exchange Commission .

Kahneman, D. and A. Tversky, 1979. Prospect theory: An analysis of decision under risk, Econometrica 47, 263-291.

Lynch, A.W. and D.K. Musto, 2003. How investors interpret past fund returns, Journal of Finance 58, 2033-2058.

Nanda, V., M.P. Narayanan, and V.A. Warther, 2000. Liquidity, investment ability, and mutual fund structure, Journal of Financial Economics 57, 417-443.

O'Neal, E., 2004. Purchase and redemption patterns of U.S. equity mutual funds, Financial Management 33.1, 63-90.

Polwitoon, S. and O. Tawatnuntachai, 2008. Emerging market bond funds: A comprehensive analysis, The Financial Review 43, 51-84.

Shefrin, H.M. and M. Statman, 1985. The disposition to sell winners too early and ride losers too long: Theory and evidence, Journal of Finance 40, 777-792.

Sirri, E.R. and P. Tufano, 1998. Costly search and mutual fund flows, Journal of Finance 53, 1589-1622.

Zitzewitz, E., 2006. How widespread was late trading in mutual funds? American Economic Review: Papers and Proceedings 96, 284-289.

\section{Citing Literature}

Martin Rohleder, Dominik Schulte and Marco Wilkens, Management of flow risk in mutual funds, Review of Quantitative Finance and Accounting, 48, 1, (31), (2017).

Nick Baltas and Dimitrios Karyampas, Forecasting the equity risk premium: The importance of regimedependent evaluation, Journal of Financial Markets, (2017).

Diego Víctor de Mingo-López and Juan Carlos Matallín-Sáez, Investing in mutual funds: the determinants of implied and actual net cash flows, Applied Economics, 49, 60, (5962), (2017).

Yeonjeong $\mathrm{Ha}$ and Kwangsoo Ko, Why do fund managers increase risk?, Journal of Banking \& Finance, 78, (108), (2017).

Asil Oztekin, Information fusion-based meta-classification predictive modeling for ETF performance, Information Systems Frontiers, (2016).

Yeonjeong $\mathrm{Ha}$, Bong Soo Lee, Miyoun Paek and Kwangsoo Ko, Structural VAR Approach to Mutual Fund Cash Flows: Net Flows, Inflows, and Outflows, Asia-Pacific Journal of Financial Studies, 44, 1, (59-87), (2015).

Martin Rohleder, The Relation between Past Flows and Future Performance: Simple Investment Strategies in the Mutual Fund Sector, International Journal of Financial Studies, 3, 4, (3), (2015).

Yoshikatsu Shinozawa and Andrew Vivian, Determinants of money flows into investment trusts in Japan, Journal of International Financial Markets, Institutions and Money, 37, (138), (2015).

Kwangsoo Ko, Yaping Wang, Miyoun Paek and Yeonjeong Ha, The Flow-Performance Relationship of Chinese Equity Mutual Funds: Net Flows, Inflows, and Outflows, Asia-Pacific Journal of Financial Studies, 43, 2, (273-296), (2014). 
Brian M. Lucey and Michael Dowling, Cultural Behavioral Finance in Emerging Markets, Emerging Markets and the Global Economy, 10.1016/B978-0-12-411549-1.00014-4, (327-346), (2014).

2014 47th Hawaii International Conference on System Sciences (HICSS) Waikoloa, HI 2014 47th Hawaii International Conference on System Sciences IEEE , (2014). 978-1-4799-2504-9 Asil Oztekin, Kyle Best and Dursun Delen Analyzing the Predictability of Exchange Traded Funds Characteristics in the Mutual Fund Market on the Flow of Shares Using a Data Mining Approach , (2014). 7797886758700 , 10.1109/HICSS.2014.104 http://ieeexplore.ieee.org/document/6758700/

Susan E.K. Christoffersen, David K. Musto and Russ Wermers, Investor Flows to Asset Managers: Causes and Consequences, Annual Review of Financial Economics, 6, 1, (289), (2014). 